\title{
Ancestor portraits at Mogao Cave 231
}

\author{
Winston Kyan
}

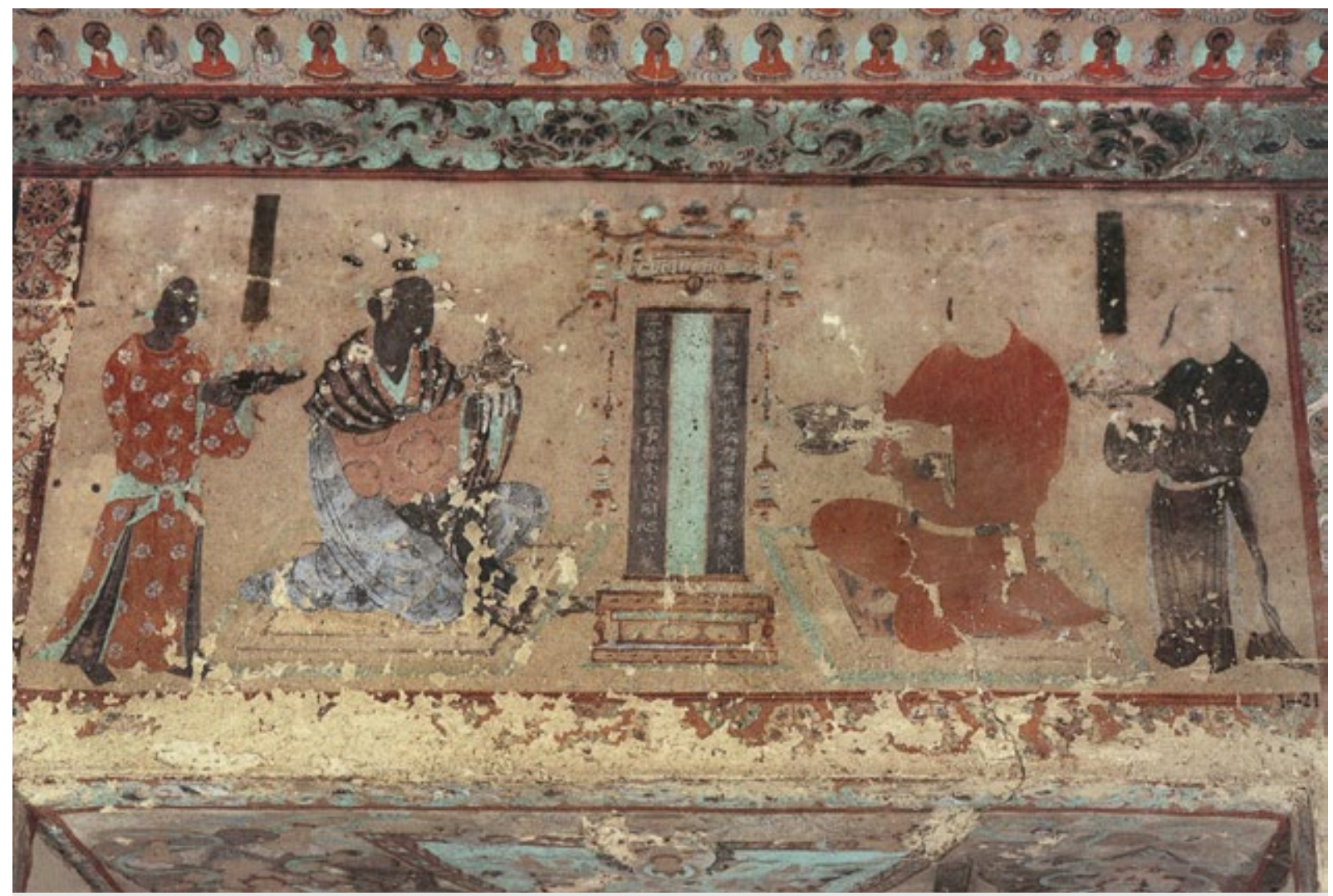

Ancestor Portraits at Mogao Cave 231, ca. 839 CE

The nearly five hundred decorated Mogao Caves at Dunhuang house an estimated 484,250 square feet (45,000 square meters) of murals that shed light on Chinese Buddhist practices from the fifth to fourteenth centuries. Cave 231, circa 839 C.E., is the family cave of the distinguished Yin family. On the eastern wall of the cave interior, a painted figural group above the entrance marks a notable shift in patronage practices at this important Silk Road site. The integration of these "secular" figures into a Buddhist cave complicates the separation established by both medieval Chinese authors and modern scholars of Buddhist art between practices of familial commemoration and religious devotion. Medieval authors argued that native Chinese values of Confucian filial piety were incompatible with imported practices of Buddhist social renunciation. Modern scholars have similarly described filial piety and Buddhist devotion as falling into the mutually opposing categories of the secular and the sacred, respectively. This essay recognizes the secular and the sacred, as well as the artistic, historical, and religious values of Confucianism and Buddhism, as cultural constructs. Accordingly, the ancestor portraits in Cave 231 at Mogao challenge the historical tendency to represent these categories in strict opposition to one another, demonstrating instead their fluid and contingent nature. 
Measuring approximately 39" $(100 \mathrm{~cm})$ in width and 30" $(76 \mathrm{~cm})$ in height, the Cave 231 image comprises four figures arranged two on either side of an inscribed tablet. ${ }^{1}$ To the left, a woman clothed in layers of multi-colored fabric kneels facing the central tablet. In one hand, she holds forth a rounded censer. On the right, a man dressed in a simple red robe kneels in the same manner and extends a long-handled censer. A standing female attends the kneeling woman, while a standing male attends the kneeling man. The attendants hold offerings of flowers and are represented in smaller scale than the kneeling figures. The painter has employed hierarchical scale to emphasize the attendants' lesser importance as compared to the central figures. A rectangular border referencing intricate textile patterns frames the entire group. Over time, the oxidation of pigments containing iron has darkened skin tones that would originally have tended toward a light orange or tan color.

The fine execution and prominent placement of these figures within Cave 231 distinguish them from other images conventionally designated as secular donor images in Dunhuang art. Moreover, the quality and location of these figures indicate a key development in the integration of filial piety with Buddhist devotion at the Mogao site. Medieval Chinese authors frequently described filial piety as the antithesis of Buddhist goals of renouncing family ties. Such goals of renunciation were characterized at the time as Indian and foreign in contrast to the native Chinese concept of filial piety. The incorporation of these secular figures into Buddhist family caves, however, provides compelling evidence that the lines between filial piety and Buddhist devotion were not always as sharply drawn as medieval Chinese textual rhetoric might imply.

The presence of textual evidence further complicates the function of these figures in Cave 231. A curious discrepancy appears when the cave inscription located between these two figures is compared with the text of the merit record that details the construction of Cave 231. This merit record is preserved in two manuscript transcriptions (P.4640 and P.4638) in the Bibliothèque nationale in Paris. While the merit record clearly identifies the primary patron of Cave 231 as "the retired gentleman" Yin Jiazheng, no mention of Yin Jiazheng is made in the cave inscription between the two figures. The inscription identifies the male figure as "the deceased father" followed by his official titles and the woman as "the deceased mother" born into the Suo family. In comparing the titles and genealogical details in the cave inscription with the information from the manuscript merit record, it becomes clear that the painted male figure represents Yin Bolun, Yin Jiazheng's father, and that the female figure represents Lady Suo, Yin Jiazheng's mother.

The actual patron of Cave 231, Yin Jiazheng, is neither mentioned in the inscription nor, by extension, depicted in the figural grouping. The resulting function of the kneeling figures above the eastern entrance thus becomes something other than a donor image recording an act of patronage. The precise generational relationships indicated by the inscription ("deceased father," "deceased mother") suggest that these figures should be viewed not as donor images but rather as ancestor portraits. They not only express the filial devotion of Yin Jiazheng toward his parents, but also transform them into visual surrogates that direct Buddhist devotion through the filter of ancestor worship and filial 
piety.

Notably, the artist placed these figures above the eastern cave entrance opposite a Buddha niche in the western wall. Over time, donor images at Mogao became progressively larger and more prominent. Nevertheless, they were consistently placed on the lower levels of the cave walls, while the explicitly sacred Buddhist subjects occupied higher positions. The elevated location of the ancestor portraits in Cave 231 (and in other ninth- and tenth-century caves such as Caves 9, 12, 20, 138, 144, 156, 359) stands in direct contrast to this convention; these ancestor portraits appear on the highest registers of the cave walls.

Contrary to earlier arguments by other scholars to this effect, the prestige implied by the location of these purportedly secular figures does not here indicate a non-Buddhist or irreligious cave. The kneeling postures nuance the elevated position of the figures. Not only are the figures represented as kneeling, but they are also depicted in threequarter profile. This gives the viewer the impression that the figures are turning away from the surface of the wall and looking across the cave towards the western Buddha niche. Furthermore, the distinctive pose of one raised knee is shared by sculptures of bodhisattvas represented in western Buddha niches from the same period.

In sum, the identifying inscription of these figures, their characteristic postures, and their location above the eastern entrance of Cave 231 signal an early manifestation of an artistic innovation in ninth- and tenth-century family caves that would profoundly affect the design of Mogao caves. By repurposing the donor portrait genre to create ancestor portraits, these images directly integrated filial piety into the visual conventions of Buddhist iconography. In doing so, they challenge us to reconsider rigid oppositional categorizations of the secular and the sacred in the study of medieval Chinese Buddhist art. $^{2}$

(c) Winston Kyan

\section{Citation Guide}

1. Winston Kyan, "Ancestor portraits at Mogao Cave 231," Object Narrative, in Conversations: An Online Journal of the Center for the Study of Material and Visual Cultures of Religion (2014), doi:10.22332/con.obj.2014.26

Kyan, Winston. "Ancestor portraits at Mogao Cave 231." Object Narrative. In Conversations: An Online Journal of the Center for the Study of Material and Visual Cultures of Religion (2014). doi:10.22332/con.obj.2014.26

\section{Notes}

1. The dimensions of the entire figural grouping is my estimation based on 
measurements provided by the Dunhuang Research Academy for the inscription between the figures, which measure 15 " $(38 \mathrm{~cm})$ in height and 4 " $(10 \mathrm{~cm})$ in width. See Dunhuang Mogaoku gongyangren tiji, ed. Dunhuang yanjiuyuan (Beijing: Wenwu chubanshe, 1986), 105.

2. For a larger study of this development, see Winston Kyan, "Family Space: Buddhist Materiality and Ancestral Fashioning in Mogao Cave 231," The Art Bulletin 92: 1-2 (March/June 2010): 61-82.

\section{Yale}

Copyright 2016 Yale University All rights reserved. 